\title{
Relating Electricity Differentials to Nigeria per Capita Income: A Distributed Lag Approach
}

\author{
Nwosu Chinedu Anthony ${ }^{1} \&$ Marcus Samuel Nnamdi ${ }^{1}$ \\ ${ }^{1}$ Department of Economics, Achievers University, Owo, Nigeria \\ Correspondence: Marcus Samuel Nnamdi, Department of Economics, Achievers University, Owo, Ondo State, \\ Nigeria. E-mail: marcus2001ng2000@yahoo.com,marcus2001ng2000@gmail.com
}

Received: February 22, 2013

Accepted: April 26, $2013 \quad$ Online Published: May 12, 2013

doi:10.5430/ijba.v4n3p86

URL: http://dx.doi.org/10.5430/ijba.v4n3p86

\begin{abstract}
The purpose of this study is to proffer an explanation of comparative low per capita income in Nigeria using data on electricity loss. We hypothesized that per capita income is a function of electricity loss which we defined as the differential between actual electricity generated and actual electricity consumed. Using time series data from 1970 to 2005, we estimated a distributed lag model with Newey-West HAC standard errors. From the estimated model which was truncated at three lag lengths, we established an inverse relationship between per capita income and total electricity loss with all the distributed lag variables being statistically significant. The implication of this result is that electricity loss generally affect national output negatively which in turn reduces our per capita (income of the people). Policy measures that will ensure adequate protection and system stability of the existing fragile transmission and distribution network, the strengthening and expansion of the transmission and distribution infrastructure will reduce electricity loss and eventually improve our per capita income.
\end{abstract}

Keywords: captive power supply, transmission and distribution loss

\section{Introduction}

Electricity is the cornerstone on which every modern economy depends. Its steady supply therefore becomes essential for economic performance, poverty reduction and enhanced standard of living. Considering the crucial role of electricity in the economy, Aderibigbe (2010) opine that electricity delivery system (transmission and distribution networks) must be robust and flexible enough, every second of the day and every day of the year to accommodate the nations demand for electricity and deliver regular, reliable and affordable electricity especially in the production economy. Sadly, for nearly three decades, Nigerians power sector has failed to supply sufficient electric power to propel the development of the various sectors of the economy. At the moment, Nigeria is faced with an unprecedented energy crisis in spite of the abundance of energy resources, resulting to the inability of the electricity supply operators dominated by the government -owned PHCN to provide sustainable, reliable and efficient electricity to the different consumers (i.e. residential, commercial and industrial consumers). Current electricity crisis characterized by, low voltage, blackout, brownout and general load shedding generally impinge upon the level of economic activities in the country. Ugwu, Nwankwojike, Ogbonnaya and Ekoi (2012) attributed the present electricity crisis to transmission and distribution loss and under-utilized capacity. Record of electricity generation in Nigeria show an annual double digit transmission and distribution loss considered to be too large given the adverse effect on the economy.

The underutilization of the installed capacity coupled with transmission and distribution loss of electricity have pushed the Nigerian electricity consumer into self generation of electricity usually referred to as captive power supply. The socio-economic implication of electricity transmission and distribution loss forms the objective of this study. Even though huge literature on electricity and economic growth abound, there is no known study to the authors on the dynamic relationship between electricity loss and per capita income in Nigeria. This is the gap which this study is hoped to fill. We believed that a study like this is apt in order to obtain accurate electricity forecasting, supply and demand management as well as for efficient and effective policy decisions. The rest of this work is organized as follows: section 2 covers electricity generation, supply and loss patterns while section 3 presents the literature review. Section 4 is on methodology and data sources, section 5 covers the presentation and analysis of results while section 6 presents the conclusion and policy implication of the study. 


\section{Electricity Generation, Supply, Consumption and Loss Pattern}

Nigeria is blessed with abundant natural energy carrier sources. Fossil are hydrocarbon substances which include crude oil, natural gas, bitumen and coal. Inexhaustible renewable energy sources like solar, wind and hydro are equally available on periodic or cycle basis. In spite of these, Nigeria still suffers inadequate supply of electricity. The epileptic electricity supply has affected the income generating opportunities of the informal sector (the developing agent of any economy) and result to a high cost of doing business. Sambo (2006) shows that only 40 per cent of the 150 million Nigerians have access to electric power. Of this figure, only 15 per cent of the rural dwellers (that constitutes 70 per cent of the population) have access to electric power.

Before 1950, the installed generation capacity of the Nigerian electric power sector was less than $20 \mathrm{MW}$. With the establishment of Electric Company of Nigeria in 1951 to coordinate the distribution of electricity, the coming on board of the Nigerian Dam Authority and eventual formation of the National Electric power Authority in 1972(following the abolition of ECN and NDA), the generating capacity rose to $1030 \mathrm{mw}$ with the peak demand of $390 \mathrm{mw}$. With the commissioning of $600 \mathrm{mw}$ Shiroro Power Station in 1990, the installed capacity rose to 6000mw. We attribute the increase in installed and generating capacity from 1970-1979 to:

(1) The post-war reconstruction and rehabilitation program and

(2) The relative newness of some of the power stations then. Average generating capacity within this period was $384.4 \mathrm{mw}$ while average installed capacity stood at $1097.8 \mathrm{mw}$.

However, the rate of growth of generating capacity fell in the 1980s to 7.5 per cent and 2.5 per cent in the 1990 s for lack of investment in the sector and lack of maintenance of existing infrastructure. A critical inspection shows that average electricity generated within the period under study (1970-2005) was $1277.4 \mathrm{mw}$ while average electricity loss was 479.93 throughout this period. Highest electricity generation occurred in 2005 when a total of $2779.3 \mathrm{mw}$ was generated while lowest generation of $176.6 \mathrm{mw}$ occurred in 1970. Within this period, a total of $45984.4 \mathrm{mw}$ of electricity was generated, out of which only $29192.4 \mathrm{mw}$ of electricity was actually consumed which represents 63.5 per cent of electricity generated with the balance as the loss within the period. On the average, $810.9 \mathrm{mw}$ was consumed annually. Records show that highest electricity consumption in the country was in 2005 when $1873.1 \mathrm{mw}$ was consumed while the lowest consumption period was in 1970 with a total consumption of $145.3 \mathrm{mw}$. Generally, electricity generation and consumption was low during the early 1970s because of the civil war. However with the reconstruction and rehabilitation programs, both installed and generating capacities increased. From 1972-1992 electricity generations increased at an average rate of 11.6 per cent per annum whereas it was 4.5 per cent from 1993-2005.

The energy supply system is normally surrounded with transformation, transportation transmission and conversion processes. Bhattacharyya (2011) observed that all these processes involve a significant amount of losses and that reducing losses can reduce pressure on energy demand. For instance, a community needs $10 \mathrm{mw}$ of electricity which involves 5 per cent conversion, transmission and distribution loss. If the thermal station operates at 90 per cent efficiency and produces 100 per cent electricity from the energy source, the generating rate from the installed capacity is 30 per cent. To supply this $10 \mathrm{mw}$, the power station needs produce $10.05 \mathrm{mw}$ of electricity. If the efficiency of the station is 90 per cent, its input requirement of the station is $11.17 \mathrm{mw}$. Since 100 per cent electricity is produced from the energy source, the energy source requirement is still $11.7 \mathrm{mw}$. But to do this, considering its installed capacity, it has to generate $38.8 \mathrm{mw}$. This shows the effect of loss and the need for efficiency at various stages of energy supply system.

Highest electricity loss stood at 62 per cent in 1981and has since then exceeded electricity generation. Lowest electricity loss was in 1978 at 3.5 per cent. Only in 1974 did records show no electricity loss, a situation difficult to explain given the undeveloped state of the sector in the country at that time. However, the situation may be attributed to the post- war reconstruction and rehabilitation program going on in the country then. While the average growth rate of electricity generation per annum within the period stood at the rate of 7.7 per cent, average growth rate of electricity loss per annum stood at 9.7 per cent. On the other hand, GDP average growth rate stood at 14.5 per cent per annum within the same period. Sambo (2008) using 2005 as the base year, had projected a demand of $5746 \mathrm{mw}$ in 2005 giving a 7 per cent growth rate GDP. But actual electricity generated for that year was 2779.3 mw while actual consumption was $1873.1 \mathrm{mw}$ leaving a loss of $906.2 \mathrm{mw}$ which was 48.4 per cent of the generated electricity in that year alone and a deficit of $3872.9 \mathrm{mw}$ or 206.8 per cent of unconsumed electricity based on what was projected. Figure 1 below shows the pattern rate of electricity generation and loss while Figure 2 reveals the relationship that exists between rates of electricity loss and PCI. 


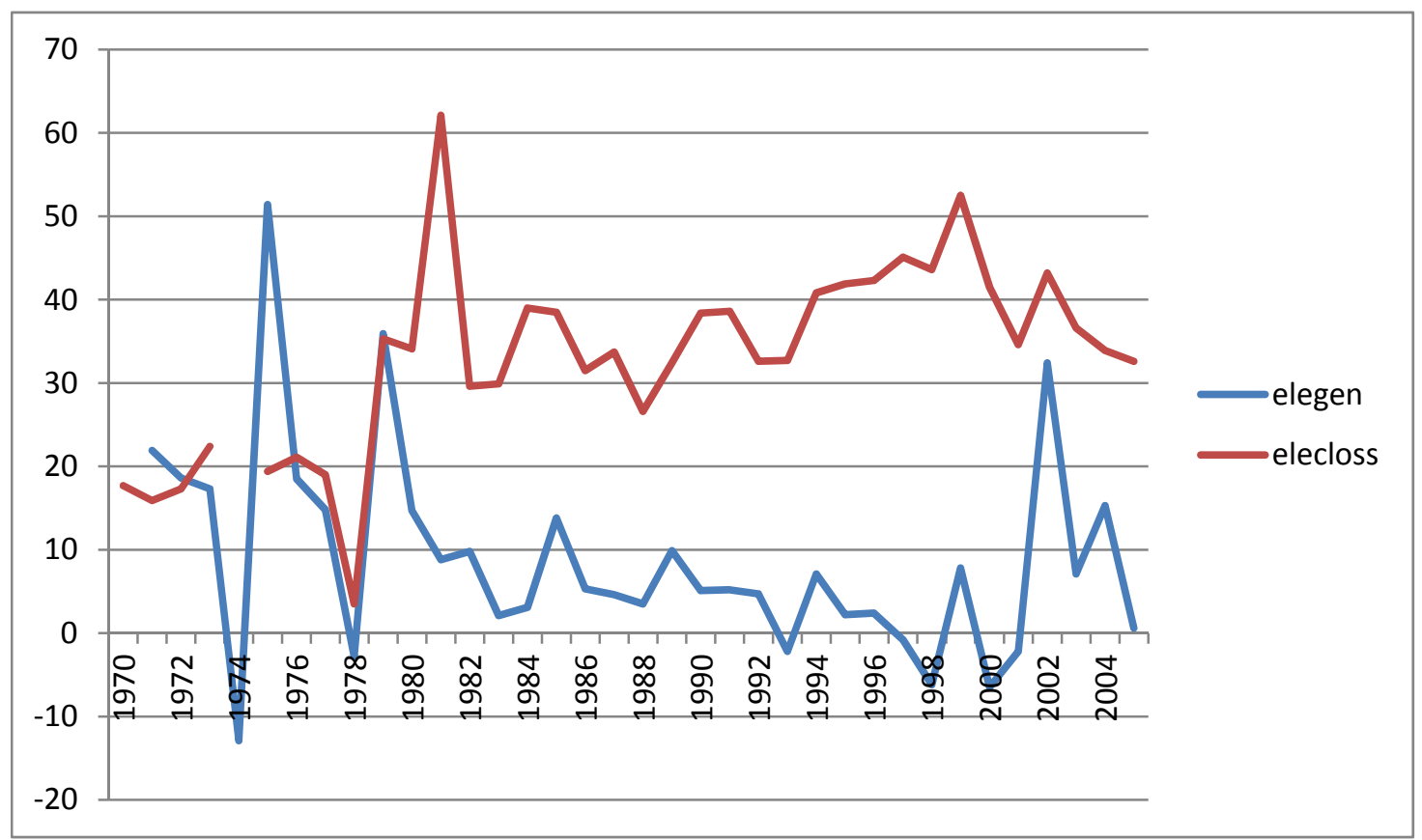

Figure 1. Rates of electricity generated and electricity loss

Source: by Authors. (elegen $=$ total electricity generated and elecloss $=$ total electricity loss)

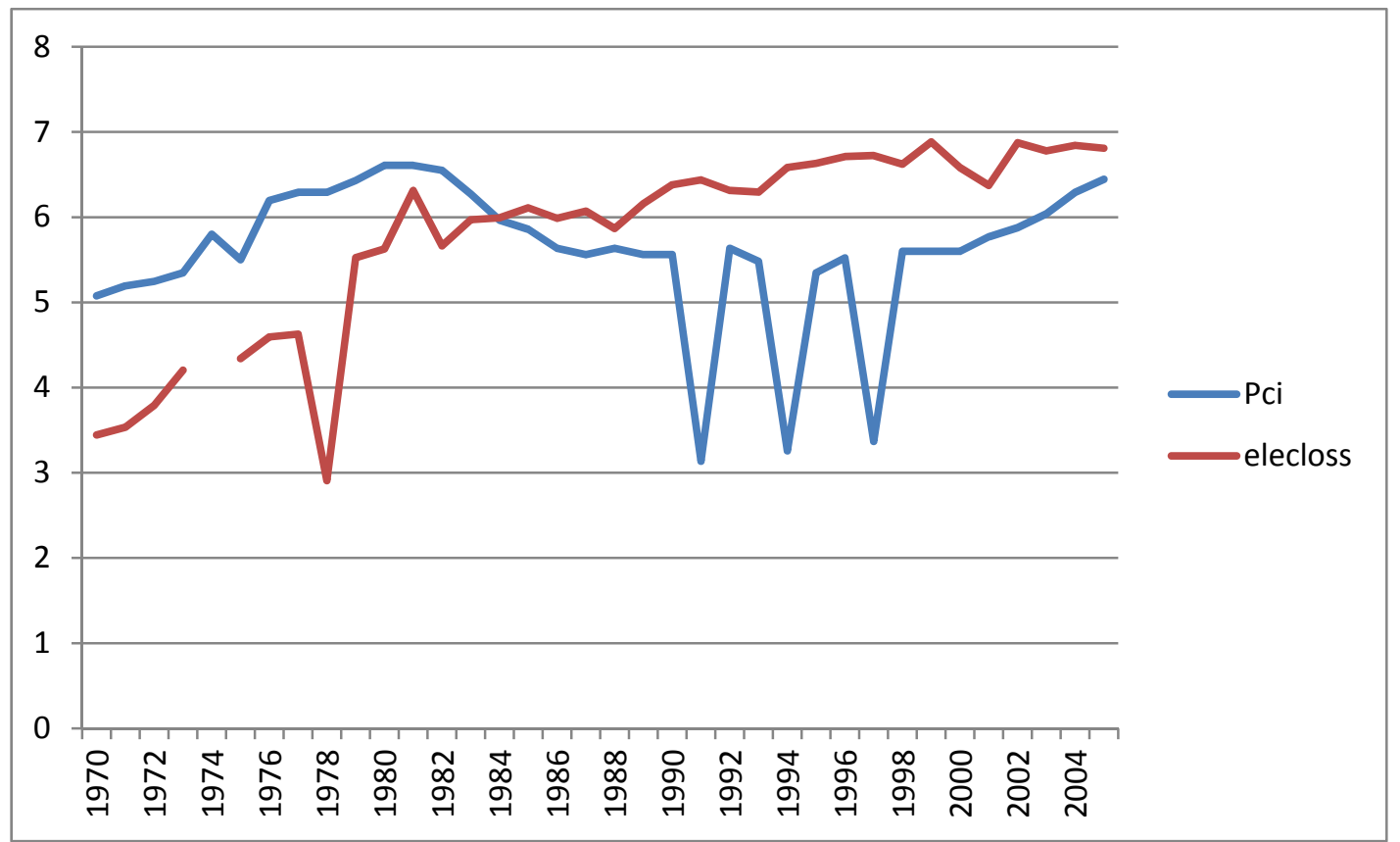

Source: by Authors

Figure 2. Natural log of electricity loss and PCI

The interplay between the two variables shows that Pci had risen above electricity loss from 1970 up to 1984 after which electricity loss rose faster and above it up to 2005 . Hence, while the annual growth of Pci stood at 3.9 per cent, annual growth of electricity loss stood at 9.7 per cent. An important issue to note is the fact that average electricity contribution to GDP within the period of our study is 0.78 per cent even though it constituted 81.7 per cent of total utility. A major issue in the Nigerian electricity industry is reducing the double digit electricity loss to single digit to meet the internationally acceptable standard of 15 per cent (Iwayemi 2008; Ugwu etal 2012). Kasita (2012) notes that a reduced power loss means consumers will pay less for energy bills since power tariffs are computed by 
factoring power losses, interest rates, inflation rates, maintenance and operation of generation, fuel prices and transmission and distribution costs.

Following various reforms in the power sector in 2005, NEPA was unbundled to 18 companies (eleven distributions, six generating and one transmission). The idea is to put to an end NEPA's monopoly and to encourage independent power producers to generate and distribute electric power. The unbundling of NEPA has led an increased installed capacity of $8227 \mathrm{mw}$ in 2010 with available installed capacity of $4058 \mathrm{mw}$ and actual generating capacity of 3716 (Aderibigbe, 2010). Experts have projected national demand of $10,000 \mathrm{mw}$ in 2012. With this, it shows that there is a national generation deficit of about $6000 \mathrm{mw}$ considering the acclaimed $4000 \mathrm{mw}$ generated by the sector recently. The supply estimate of $4000 \mathrm{mw}$ in 2012 with a population of 150 million is at the risk of development. Comparatively, South Africa with a population of about 50 million has available generating capacity of $40000 \mathrm{mw}$ ( 800 watts per capita) while Brazil has a generating capacity of $100000 \mathrm{mw}$ with a population of 201 million people (498 watts per capita).

\section{Literature Review}

The centrality of electricity supply and consumption to the development and growth of global economies has captivated many energy economists and analysts. Sanchis (2007) in quantifying the contribution of electricity to Spanish economic growth in the twentieth century posits that electricity as an industry is responsible for a great deal of output. Stern (2003) in surveying the relationship between Energy and Economic Growth in the U.S discovered that energy use and economic activity are found to be tightly coupled when the composition of final energy use is taken into account. Attinay and Karagol (2005) also found a strong evidence for unidirectional causality running from electricity consumption to income. According to them, this implies that the supply of electricity is vital to meet the growing electricity demand and to sustain economic growth in Turkey. Studying the impact of electricity supply on economic growth in Sri Lanka, Morimoto (2001) discovered that energy consumption and economic growth are highly correlated. Alam (2006) in a similar study in U.S examined energy as a factor of production and observed that the economy consists of streams of energy conversions that direct energy to the production of goods and services. He further added that energy allows a better grasp of the tasks performed by labor and capital, raises the prospects of examining growth as the speeding up of machines and identifies energy as an important source of growth. Shahbaz and Lean (2011) studied the dynamics of electricity consumption and economic growth in Pakistan. The findings show bi-directional granger causality between electricity consumption and economic growth. Further findings revealed that energy conservation policy may decline growth which will in turn lower electricity demand.

Ayodele (2004) posit that the quest to rapidly and firmly put the Nigerian economy on course of economic development is technically, a function of adequate and distribution of energy, particularly electricity. Ubi Effiom, Okon and Oduneka (2012) took an econometric analysis of the determinants of electricity supply in Nigeria and discovered that power loss on the average is about 40 per cent per annum. They further observed that power loss is statistically a significant determinant of electricity supply in Nigeria. George and Oseni (2012) in examining the relationship between electricity power supply and unemployment rates in Nigeria established that the course of unemployment in the country can be traced to inadequate and unstable power supply to the industrial sector induced by un-generated and wasted electricity power. Odularu and Okonkwo (2009) considered the contribution of energy consumption and economic performance in Nigeria and found that increased energy consumption is a strong determinant of economic growth. Finally, Udah (2010) showed that industrial development, electricity supply technology and capital employed are important determinants of economic development.

All literature reviewed confirm the role of adequate electricity supply to the economic growth of any nation. Our study however, will take a step further to relating electricity differentials, in this case electricity loss to per capita income for the period 1970-2005.

\section{Methodology}

\subsection{Distributed Lag Econometric Model}

The dynamic model has been extensively used to forecast economic time series. The motivation for this is that contemporaneous and past values of a variable can help in determining the present and future values of another variable (Stock and Watson, 2007). Thus, the lags of a variable $X_{t}$ determine the effects on another variable $Y_{t}$.

To achieve this dynamics, contemporaneous and distributed lags of the independent variable are used to determine the immediate and cumulative impact on the dependent variable. Generally, a bivariate distributed lag model can be written as 


$$
Y_{t}=\alpha+\beta_{0} X_{t}+\beta_{1} X_{t-1}+\beta_{2} X_{t-2}+\beta_{3} X_{t-3}+u_{t}
$$

where the above model is a finite distributed lag that we truncated at lag three . Usually, the t subscript is used to denote that we are dealing with times series. Here, the impact multiplier is given by $\beta_{0}$ while the cumulative dynamic multiplier is the sum of all the $\beta_{s}$.

However, the inherent problem with this type of econometric model is that of exogeneity. In the distributed lag model, the error term is exogenous if it is uncorrelated with its current and past values given the independent variables. Mathematically, exogeneity for finite model of lag three is written thus

$$
\mathrm{E}\left(u_{t} \mid X_{t}, X_{t-1}, X_{t-2}, X_{t-3}\right)=0
$$

Omitted factors that are included in the error term introduce serial correlation in the error term. As a result, the general OLS standard errors are inconsistent and yields misleading inferences. To overcome this estimation problem using OLS method, heteroskadisticity and autocorrelation-consistent (HAC) standard errors are used. For this study we used Newey-west HAC standard errors (Newey and West, 1987). Finally, this model is estimated under the assumption that the variables are jointly stationary and free from perfect multicollinearity.

\subsection{Data Sources}

The time series data on electricity generation and consumption used for this study was obtained from central bank of Nigeria statistical bulletin 2006. Due to lack of data on electricity generation and consumption beyond 2005, we restricted this study to be from 1970 to 2005 . The data on per capita income (PCI) measured in dollars was obtained from World Bnk Natioal accout data and OECD national accounts data. We computed total electricity loss per year as the differential between total electricity generated and total electricity consumed all measured in megawatts per hour. That is

$$
T E L=T E G-T E C
$$

Where

TEL is total electricity loss

TEG is total electricity generated

TEC is total electricity consumed.

\subsection{Model Specification}

We hypothesize that per capita income is a function of total electricity loss.

That is

$$
P C I=f\left(T E L_{t}, T E L_{t-1}, T E L_{t-2}, T E L_{t-3}\right)
$$

The model to be estimated is given as

$$
\text { LPCI }{ }_{t}=\beta_{0}+\beta_{1} \text { LTEL }{ }_{t}+\beta_{2} \text { LTEL }_{t-1}+\beta_{3} \text { LTEL }_{t-2}+\beta_{4} \text { LTEL }_{t-3}+u_{t}
$$

Where

$L P C I \quad$ is the natural log of per capita income

$L T E L$ is the natural log of total electricity loss up to lag three.

$u$ is the stochastic error term.

\section{Apriori expectation}


It is expected that per capita income and total electricity loss should be inversely related. Therefore LTELS are expected to have negative sign.

\section{Presentation of Result}

One of the conditions for the use of a dynamic model is that the variables must be stationary. Below is the result of the unit root test on $L P C I$ and $L T E L$. We tested the order of integration by ADF statistics and used PP test as a confirmatory test.

Table 1. Unit root test for LPCI and LTEL

\begin{tabular}{llccc}
\hline Variable & ADF test & \multicolumn{2}{c}{ PP test } \\
\cline { 2 - 5 } & Level & First difference & Level & First difference \\
\hline LPCI & -1.312 & $-7.305^{*}$ & -1.803 & $-2.828^{* *}$ \\
LTEL & $-2.759^{* *}$ & $-9.768^{*}$ & -2.501 & $-14.514^{*}$ \\
$5 \%$ Critical value & -2.972 & -2.975 & -2.972 & -2.975 \\
10\% Critical value & -2.618 & -2.619 & -2.618 & -2.619 \\
\hline
\end{tabular}

$*$ and $* *$ represents $5 \%$ and $10 \%$ significance respectively.

From Table 1 above, it can be seen that both LPCI and LTEL are $I$ (1) processes. That is, they are stationary at their first difference. We used the first difference of these variables for our estimation even though we observed that LTEL was level stationary at $10 \%$ level of significance.

\subsection{Empirical Result and Analysis}

Presented below is the result of the OLS estimated dynamic model with three lag lengths. Below the estimated coefficients of the distributed lag variables are the Newey-West standard errors which we truncated at three lags (Note 1). Similarly, the Akaike Information Criterion was used to select maximum lag length for the distributed lag coefficients.

$$
L P C I_{t}=\underset{(0.0058)}{0.026}-\underset{(0.0059)}{0.079} \text { LTEL } t \underset{(0.0046)}{0.044} L T E L t-1_{(0.0048)}^{-0.078} L T E L t-2-\underset{(0.0033)}{0.053} L T E L t-3
$$

From the estimated model, the contemporaneous and distributed lag variables possess the expected negative sign. This confirms that per capita income and total electricity loss are inversely related. More so, all the distributed lag variables are statistically significant as can be seen from their respective standard errors. Since this is a double-log model, we interpret the results as elasticity (Gujarati and Porter, 2009). The impact multiplier (immediate effect) of total electricity loss on per capita income is -0.079 which shows that PCI is responsive to TEL to the tune of 0.079 percent contemporaneously. In other words, as total electricity loss increases on the average by 0.079 percent, per capita income decreases on the average by 0.079 percent. Similarly, per capita income on the average responds to total electricity loss three consecutive periods later by decreasing 0.044 percent the first period and 0.078 percent and 0.053 percent in the second and third period respectively. The cumulative dynamic multiplier (effect) on per capita income of total electricity loss three periods later according to our estimated model is given by 0.254 percent $(0.079+0.044+0.078+0.053)$. Put simply, at cumulative total electricity loss of 0.254 percent over the three year period, per capita income will decline on the average by 0.254 percent. The R-squared and Adjusted R-squared for the estimated model are 0.34 and 0.25 respectively.

In order to ensure the adequacy of our model over the study period, we carried out further diagnostic test. Multicollinearity was checked using Variance Inflation Factor (VIF). A variable is said to be highly collinear if the VIF of that variable exceeds 10 (Gujarati and Porter, 2009). Table 2 below reveals that none of the variables exceeded the benchmark for centered and uncentered VIF. Therefore, the model is free from Multicollinearity. Furthermore, we tested for the normality and stability of the OLS residuals using Jarque-Bera normality test and CUSUM/CUSUMSQ (Brown, Durbin and Evans, 1975) respectively (see Figures 3 and 4 below). The results show that the residuals are normal with p-value of 0.88 while CUSUM/CUSUMSQ test statistics fall within 5\% level of significance for the critical bounds confirming the stability of the parameters over the study period. 
Table 2. Results of the distributed lag regression of LPCI and LTEL

\begin{tabular}{|c|c|c|c|c|}
\hline \multicolumn{5}{|c|}{ Dependent variable: $\mathrm{LPCI}_{t}$} \\
\hline Regressor & & \multicolumn{3}{|c|}{ Summary of diagnostic statistics } \\
\hline \multirow[t]{2}{*}{$\mathrm{LTEL}_{\mathrm{t}}$} & -0.079 & R-squared & \multicolumn{2}{|c|}{0.35} \\
\hline & $(0.0059)$ & Adj R-squared & \multicolumn{2}{|c|}{0.25} \\
\hline \multirow[t]{2}{*}{ LTEL $_{t-1}$} & -0.044 & Durbin-Watson & \multicolumn{2}{|c|}{2.4} \\
\hline & $(0.0046)$ & jarque-Bera pvalue & \multicolumn{2}{|c|}{0.89} \\
\hline \multirow[t]{2}{*}{ LTEL $_{\mathrm{t}-2}$} & -0.078 & \multicolumn{3}{|c|}{ Variance Inflation Factor } \\
\hline & $(0.0048)$ & Variable & Uncentered & Centered \\
\hline \multirow[t]{2}{*}{$\mathrm{LTEL}_{\mathrm{t}-3}$} & -0.053 & $\mathrm{C}$ & 2.916390 & NA \\
\hline & $(0.0033)$ & $\mathrm{LTEL}_{\mathrm{t}}$ & 7.133979 & 3.552697 \\
\hline \multirow[t]{2}{*}{ Intercept } & 0.026 & LTEL $_{t-1}$ & 9.838886 & 4.086141 \\
\hline & $(0.0058)$ & LTEL $_{t-2}$ & 2.685755 & 2.305799 \\
\hline F-stat & 3.6 & LTEL $_{t-3}$ & 3.248031 & 2.998347 \\
\hline
\end{tabular}

HAC standard errors are enclosed in parentheses under the coefficients.

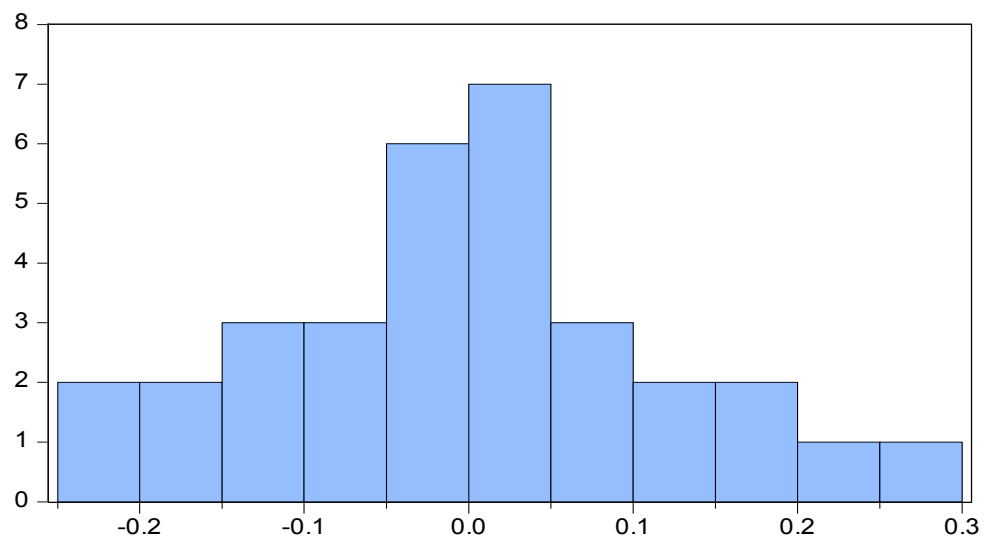

\begin{tabular}{|lr|}
\hline \multicolumn{2}{|l|}{ Series: Residuals } \\
Sample 4 35 \\
Observations 32 \\
Mean & $5.20 \mathrm{e}-18$ \\
Median & 0.000277 \\
Maximum & 0.259609 \\
Minimum & -0.215105 \\
Std. Dev. & 0.116379 \\
Skewness & 0.155315 \\
Kurtosis & 2.705527 \\
& \\
Jarque-Bera & 0.244275 \\
Probability & 0.885027 \\
\hline
\end{tabular}

Figure 3. Jarque-Bera Normality Test for OLS residuals
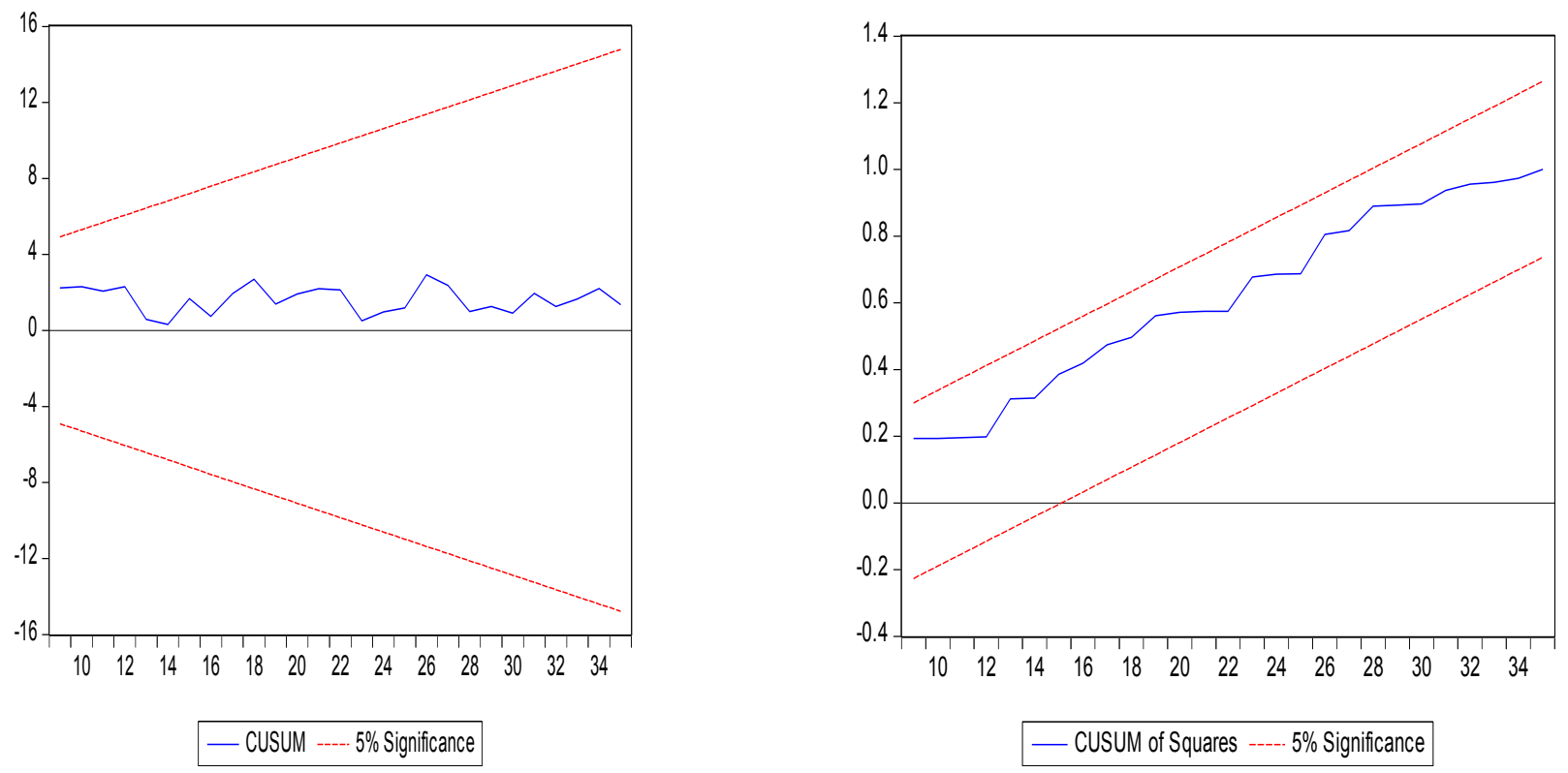

Figure 4. Plot of CUSUM and CUSUM of squared statistics 
The finding from this study is in line with previous studies concerning economic performance and electricity generation and consumption in Nigeria (Udah, 2010; Odularu and Okonkwo 2009). George and Oseni (2012) established an inverse relationship between electricity loss and employment in Nigeria which shows that electricity loss worsens unemployment level and in turn lowers general income level of the entire populace. However, no study so far concentrated on electricity loss and per capita income. Judging by previous research in this area, electricity consumption is a major determinant of output growth (Stern 2003). It follows that electricity consumption should equally influence per capita output growth (per capita income) positively. Theoretically, electricity wastages (losses) negatively influence per capita output. We established a dynamic effect on per capita income of electricity losses based on the time series data collected. Our result reveals that the per capita income of Nigeria has not been optimal due to the negative dynamic effect from electricity loss. Past and present electricity losses cause the Nigerian per capita income to be less than its optimal level. In other words, a reduction in total electricity loss is expected to improve the level of our per capita income ceteris paribus. Of greater concern is the fact that Nigeria is yet to utilize the total installed generating capacity of electricity (6000 megawatts) which is below the required level to drive our fragile economy. So it is unhealthy to lose any part of the generated electricity bearing in mind the colossal impact of such losses on output. If the current electricity loss is left unchecked, our study posits that Nigeria will continue to have suboptimal level of per capita income which is expected to affect the general standard of living of the entire population adversely.

\section{Conclusion and Policy Implication}

This study investigated the dynamic relationship between electricity losses and the Nigerian per capita income using annual data from 1970 to 2005 . The distributed lag model of total electricity loss (in log form) up to three lag length as the independent variables and per capita income (also in log form) as dependent variable was estimated. It was found that electricity loss adversely affects Nigeria`s per capita income thereby causing a less than optimal level PCI which is lower than that obtainable if there were to be losses.

Even though this study is silent on the causes of electricity loss in Nigeria, it is a fact that it exists with its attendant socio-economic problems. Based on this finding, we recommend that government should take the issue of electricity losses very serious. Measures to combat this unfriendly trend should be put in place as this will improve the general wellbeing of the economy. Such measures will include the adequate protection and system stability of the existing fragile transmission and distribution network, the strengthening and expansion of the transmission and distribution infrastructure which is constantly overloaded, establishing and enforcing a functional regulatory framework that will oversee the generation, transmission and distribution of electricity and optimal utilization of the total installed electricity generating capacity among others. These will increase both the total electricity consumed as well as economic activities in the country which will in turn improve both the level of output and output per capita (income per capita).

\section{References}

Aderibigbe, D. (2010). Power Supply to industries. Pros and Cons of Available Options. A paper presented at a conference of Nigerian society of chemical Engineers( a division of NSE).

Alam, M.S. (2006). Economic growth with energy. Retrieved $16^{\text {th }}$ September 2012, from www.economics.neu.edu/papers/documents/06-003pdf

Attinay, G., \& Karagol, E. (2005). Electricity consumption and Economic Growth: Evidence from Turky. Energy Economics, 27(2005), 849-856. http://dx.doi.org/10.1016/j.eneco.2005.07.002

Ayodele, A.S. (2004). Improving and sustaining power (electricity) supply for socio economic development in Nigeria. Retrieved 4th January 2013, from www.CBnbank.org/OWT/publications/..RD/2001/OWE-01-3

Bhattacharyya, S.C. (2011). Energy Economics: Concepts, Issues, Market and Governance. New York. Springer.

Brown, R.L., Durbin J., \& Evans J. M. (1975). Techniques for testing the constancy of regression relations overtime. J. Roy. Stat. Soc. B., 37, 149-163.

Ciarreta, A., \& Zarraga, A. (n.d). Electricity Consumption and Economic Growth: Evidence from Spain. Retrieved $13^{\text {th }}$ December 2012, from ecomod.net/sites/default/files/document-conference/ecomod2007/89

Enang, U.B. (2010). Industrial Development, Electricity Crisis and Economic Performance in Nigeria. European Journal of Economic, Finance and Administrative Sciences, 18, 1450-2275.

George, E.O., \& Oseni, J.E. (2012). The relationship between electricity power and unemployment rate in Nigeria. Australian Journal of Business and Management Research, 22(4), 10-19. 
Gujarati, D., \& Porter D. (2009). Basic econometrics. Boston: McGraw-Hill.

Iwayemi, A. (2008). Investment in Electricity generation and Transmission in Nigeria: Issues and Options. International Association for energy Economics. Retrieved 11 ${ }^{\text {th }}$ Nov, 2012, from http://resource.management6.com/Investment-in-Electricity-Generation-and-Transmission-in-Nigeria-download -w4331.pdf

Jarque C. M., \& Bera A. K. (1987). A Test for Normality of Observations and Regression Residuals. International Statistical Review, 55, 163-172. http://dx.doi.org/10.2307/1403192

Kasita, I. (2012). Uganda: Power Loss Reduction Strategy Saves Economy \$33 Million. Retrieved 3rd February 2013, from www.allafrica.com/stories/201208280925.html

Odularu, O.O., \& Okonwo, C. (2009). Does Energy Consumption Contribute to Economic Performance? Empirical Evidence from Nigeria. Journal of Economic and International Finance, 2(12), 044-058.

Sambo, A.S. (2006). Renewable Energy Electricity in Nigeria: The Way Forward. A paper presented at the renewable electricity policy conference. Shehu Musa Yar’adua centre. Abuja.

Sambo, A.S. (2008). Matching Supply with Demand. Paper presented at the National Workshop on the Participation of State Governments in the Power Sector: Abuja. Retrieved 25 ${ }^{\text {th }}$ May 2012, from www.iaee.org/publication/newsletterdl.aspx $? \mathrm{id}=56$

Sanchis, M.T. (2007). Quantifying the contribution of electricity to Spanish economic growth during the twentieth century. Paper presented at the 111 Iberometrics Valencia, March 23-24.

Shahbaz, M., \& Lean, H.H. (2011). The Dynamics of Electricity Consumption and growth: A Revisit Study of their causality in Pakistan. Retrieved 2nd February 2013, from www.sciencedirect.com/science/article/pci/so360544212000539

Stern, D.I. (2003). Energy and Economic Development. Unpublished manuscript, department of Economics, SAGE 3208. Rensselaer Polytechnic Institute, street troy USA.

Stock, J.H., \& Watson, M.W. (2007). Introduction to econometrics ( $2^{\text {nd }}$ ed). Boston: Pearson - Addison Wesley.

Ubi, S., Effiom, L., Okon, E.O., \& Oduneka, A.E. (2012). An Econometric Analysis of Determinants of Electricity Supply in Nigeria. International Journal of Business Administration, 3(4). http://dx.doi.org/10.5430/ijba.v3n4p72

Ugwu, H.U., Nwankwojike, B.N., Ogbonnaya, E.A., \& Ekoi, E.J. (2012). Energy and Economic losses Due Constant Power Outages in Nigeria. Nigerian Journal of Technology (NIJOTECH), 3(2).

Note

Note 1. To arrive at the chosen lag length in our model, we applied the truncation formula $m=0.75 T^{1 / 3}$ as suggested in Stock and Watson (2007). Applying this formula for T $=36$ years gives $m=3$. 